\title{
A História dos VÂNDALOS RECONSIDERADA
}

\section{Geraldo Rosolen Júnior ${ }^{1}$}

Steinacher, R. (2016). Die Vandalen: Aufstieg Und Fall Eines Barbarenreichs.KlettCotta.

Roland Steinacher, autor do livro Die Vandalen: Aufstieg und fall eines Barbarenreichs publicado em 2016 pela editora Klett-Cotta, teve seu mestrado orientado por Walter Pohl na Universidade de Viena, obtendo seu doutorado na mesma universidade em 2002 com orientação de Herwig Wolfram, um dos grandes pesquisadores austríacos do século XX, que atuou em temas como: povos germânicos, etnogênese e etnografia nos primeiros séculos da Idade Média, tal como seu antecessor Reinhard Wenskus. Ao lado de Walter Pohl, Roland Steinacher tornou-se um dos herdeiros dessa tradição historiográfica austríaca, o que colaborou para destacá-lo como o maior especialista na História do Reino Vândalo. Atualmente suas obras são indispensáveis para quem deseja atuar nesse campo. Atuou em diversas universidades alemãs e austríacas em ensino e pesquisa, mais recentemente, entre 2016 até 2019, como professor visitante na Universidade Hildesheim, e, em 2018, Steinacher assumiu o cargo de professor de História Antiga na Universidade de Innsbruck, sucedendo Reinhold Bichler. $^{2}$

O prefácio do livro foi escrito por Herwig Wolfram, que considerou o livro de Steinacher como uma superação do trabalho de Christian Courtois em Les Vandales et l'Afrique, publicado em 1955 e considerado um dos clássicos para esse estudo. Até 2008 o livro de Courtois era um dos poucos que abordava de modo complexo e especifico a História dos Vândalos. Em 2008, Roland Steinacher junto de Guido M. Berndt editou o livro Das Reich der Vandalen und seine (Vor-) Geschichten ${ }^{3}$ que reuniu diversos pesquisadores para explorar a História Vândala desde os primeiros vestígios

\footnotetext{
${ }^{1}$ Mestrando em História (Unifesp) e Bolsista CAPES. E-mail: grosolen.junior@ hotmail.com.

2 As informações sobre o currículo do pesquisador estão disponibilizadas no site da Universidade de Innsbruck: $\quad$ https://www.uibk.ac.at/alte-geschichte-orient/mitarbeiter/univ.-prof.-mag.-dr.-rolandsteinacher.html

${ }^{3}$ Berndt, G. M. \& Steinacher, R. (eds.) (2008). Das Reich der Vandalen und seine (Vor-) Geschichten. Verlag der Österreichischen Akademie der Wissenschaften.
} 
Mare Nostrum, ano 2020, v. 11, n. 1 .

arqueológicos até a conquista bizantina das províncias africanas em 534. Entretanto, o livro Die Vandalen: Aufstieg und fall eines barbarenreichs de 2016 foi considerado de grande importância por resultar da contribuição de um único autor, assim como Courtois havia feito na década de 1950.

Em seu livro, Steinacher explora a História dos Vândalos com uso de fontes da historiografia romana e também da cultura material como recurso complementar. A utilização de métodos e fontes da Arqueologia parece sustentar a análise para períodos em que as lacunas historiográficas não conseguem estabelecer um marco inicial na História dos Vândalos. A temporalidade que ele cobre está concentrada entre o século I até finais do século VI.

Embora ele utilize um recorte temporal grande e que não necessariamente esteve a todo momento associado à História do Império Romano, o autor acredita que os vândalos se tornaram "bárbaros romanos" ao estabelecerem seu reino dentro das fronteiras imperiais. Assim, Steinacher considerou que os vândalos haviam sido assimilados e integrados às dinâmicas políticas, sociais e econômicas do Império, mas que ainda apresentavam aspectos de enfrentamento contra as elites senatoriais e se envolvendo em conflitos religiosos, mantendo parte de sua identidade "bárbara". O termo "bárbaro" é utilizado por ele como correspondência a estrangeiro, ou mesmo a soldados. Por meio dessa mesma compreensão, ele afirma que a História dos Vândalos deve ser entendida dentro de uma esfera mais ampla do mundo romano e da própria História de Roma.

Ainda que Steinacher tenha feito essa associação, é perceptível que o autor esteja preocupado em apresentar que os conflitos religiosos durante o Reinado Vândalo nas províncias africanas se realizaram com amparo do sistema legal imperial, como estratégias de controle sócio-político na África Romana. Logo, os conflitos religiosos ocorridos durante o Reinado de Genserico teriam sido fornecidos como atributo legal comum de um magister militum romano.

Embora Steinacher não pontue de modo explícito questões relativas à etnogênese vândala, essa compreensão metodológica parece nortear todo seu livro, uma vez que, ao considerar que os vândalos haviam se tornado "bárbaros romanos", ele não os qualifica dessa maneira. Partindo da consideração que ao utilizar fontes romanas somente obteríamos a própria projeção romana sobre as identidades vândala-alana, pelo contrário, 
ele defende essa última classificação se baseando nos resultados obtidos através de sua análise etnográfica.

Ainda que não seja o objetivo dessa resenha fazer discussão aprofundada sobre a aplicação da etnogênese nos estudos tardo-antigos e medievais, podemos considerar que esse debate sobre a etnogênese não aparece no livro explicitamente, por duas razões: a primeira, por compreender que não há um questionamento considerável sobre qual linha metodológica que ele iria aderir, uma vez que ele faz parte da tradição historiográfica austríaca que privilegia a possibilidade de acessar as identidades tardo-antigas, ainda que não tenham sido autorrepresentadas; e a segunda, por considerarmos que a ausência desse debate também pode ter sido orientada pela própria editora.

Outra característica comum desse livro a qual devemos estar atentos são as citações de Conrad Mannert, que orienta até certo ponto a narrativa do autor. Steinacher justificou tais citações no início de alguns capítulos e/ou subcapítulos com a consideração de que Mannert havia sido o primeiro historiador a considerar a existência de uma "consciência popular vândala".

No primeiro capítulo, Steinacher analisa o aparecimento do termo "vândalo" a partir do século I, que ele acredita fazer referência a um grupo mais amplo que estaria associado à cultura Przeworsk. Esta cultura material pode ser localizada entre os rios Oder e o Vístula, tendo inclusive competido com a cultura Wielbark sobre o domínio da região, e teria sido esse conflito que empurrou os vândalos para as proximidades das fronteiras imperiais no Danúbio. Apesar do autor considerar que as lacunas temporais dos materiais arqueológicos e também das fontes romanas como Plínio e Tácito são um empecilho para acessar essas disputas ocorridas nos territórios germânicos, ele acredita que há indícios suficientes mostrando que a partir do século II os vândalos haviam representado uma ameaça ao Império Romano pela primeira vez através das guerras marcomanas. Após esse período de conflitos iniciais, ele considera ter ocorrido um processo de assimilação dos vândalos às fileiras dos exércitos romanos até meados do século IV.

Entre o segundo e sexto capítulo são apontados nos títulos recortes temporais que não necessariamente foram seguidos por Steinacher, pois em geral sua análise é feita a partir de delimitações temporais específicas que se assemelham bastante a uma datação 
apresentada em um capítulo publicado em $2017^{4}$. Nessa produção posterior, Steinacher considerou que a Völkerwanderung deveria ser compreendida através de um recorte temporal delimitado entre 375, com a chegada dos hunos na Panônia, até 568, com a chegada dos lombardos na Península Itálica que encerraria o processo migratório desses povos, ditos germânicos (Steinacher, 2017, 68).

Esse mesmo recorte temporal (375-568) foi atribuído ao conceito da Völkerwanderung em um livro publicado por Walter Pohl em $2005^{5}$, quando o conceito passou a ser considerado mais objetivo e menos abrangente, pois antes dessa renovação foi alvo de muitas críticas por incorporar as migrações germânicas desde o século I até o século VI. Portanto, as coincidências dessa delimitação temporal, não por acaso, evidenciam a grande influência de Walter Pohl na trajetória acadêmica de Roland Steinacher.

No segundo capítulo, o autor apresenta a retomada de hostilidades entre romanos e bárbaros e a extensiva migração de vândalos, alanos e suevos que deu origem a uma coligação de povos que durou desde a travessia do Danúbio até sua chegada e posterior divisão das províncias da Hispânia entre esses grupos. Steinacher demonstra que inicialmente o poder da coligação residia aos reis dos alanos e posteriormente, com a morte do rei alano Addax, suevos e vândalos competiram pelo poder que resultou na cisão dessa coligação de povos. É também nesse mesmo capítulo que Steinacher discute a repercussão da violência desses bárbaros presentes nas fontes romanas e como a própria ausência e enfraquecimento do poder romano colaborou para o ganho de autoridade e poder dos Reinos Pós-Imperiais, em especial na ascensão do poder vândalo nas províncias da Hispânia, assim como nos eventos que levaram os vândalos a migrarem para os territórios africanos, que tornou o Reino Vândalo em uma potência política, militar e econômica do Mediterrâneo.

Outro aspecto importante que podemos destacar desse capítulo é a caracterização de Estilicão, principal comandante dos exércitos imperiais sob Honório, como um personagem bárbaro de origem vândala de grande prestígio no Império Ocidental e que

4 Steinacher, R. Wanderung der Barbaren? Zur Entstehung und Bedeutung des Epochenbegriffs, Völkerwanderung' bis ins 19. Jahrhundert. In Wiedemann, F., Hofmann, K. P. \& Gehrke, H.-J. (Eds.). (2017). Vom Wandern der Völker. Migration Erzählungen in den Altertumswissenschaften. Edition Topoi.

${ }^{5}$ Pohl, W. (2005). Die Völkerwanderung. Eroberung und Integration. Kohlhammer. Esse recorte temporal também aparece nessa outra publicação: Pohl, W. Barbarian migrations (Völkerwanderung). In Ness, I. (Ed.). (2013). The Encyclopedia of Global Human Migration. Wiley-Blackwell. 
havia se tornado uma figura controversa. Os vândalos desejavam alcançar a mesma representatividade, poder e status que Estilicão, mas este também havia se tornado para muitos aristocratas romanos uma figura que contrastava com o crescente sentimento antigermânico que predominou durante o quinto século. Portanto, consideramos que Steinacher observa essa dicotomia nas relações entre germânicos e romanos, que também orienta sua percepção quanto aos objetivos do rei vândalo Genserico em ser reconhecido como um rei legítimo pelo Império Romano.

O terceiro capítulo aborda um período relativamente curto, entre 435, quando foi firmado um tratado de paz entre o Reino Vândalo com o Império do Ocidente, até a dissolução desse tratado em 455, com a morte de Valentiniano III e o saque de Roma pelos vândalos. Entretanto, por ser um lugar onde o autor levanta inúmeras discussões, esse capítulo é o mais longo do livro. Por isso devemos nos limitar a pontuar apenas os aspectos que consideramos como os mais importantes da narrativa desse capítulo. Em um caráter geral, podemos considerar que Steinacher teve como objetivo apresentar como o Reino Vândalo havia consolidado sua autoridade na África Romana, aproveitando os vácuos de poder deixados pelo Império por meio de conflitos religiosos e políticos préexistentes à chegada vândala, o que resultou na incorporação das comunidades africanas que estavam insatisfeitas com o domínio romano.

É também nesse capítulo que Steinacher afirma que o rei Genserico havia assumido a figura de um magister militum e que sua prática de impor a religião ariana aos membros de sua corte e também às populações africanas, perseguindo, desapropriando e exilando seus adversários políticos e religiosos, pode ser compreendida como uma situação regular do ofício de um magister militum, com atribuições garantidas pela lei romana. $\mathrm{O}$ autor também considera que as próprias relações estabelecidas entre vândalos e mouros na África haviam seguido estratégias e referenciais legais e políticos do Império. Ele explica que a colaboração dos mouros no saque de Roma de 455 havia seguido padrões de integração militar romana, e que eles estariam lutando pelos vândalos como "federados", assim como outros povos já haviam feito séculos antes pelo próprio Império. Para ele, a integração militar dos mouros como federados perdurou durante todo o Reinado Vândalo na África, de Genserico a Gelimero. Dessa forma, ele consegue sustentar que os elementos políticos, econômicos, militares e sociais haviam sido incorporados como referências ao próprio desenvolvimento identitário assumido pelos vândalos. 
No capítulo quatro, o autor apresenta as consequências do saque de Roma em 455 e a rápida escalada de violência e agressividade dos vândalos com os Impérios do Ocidente e Oriente. Ele acredita que, através dessa demonstração de poder militar, o rei Genserico desejava pressionar os Impérios Romanos a aceitarem um tratado de paz segundo seus próprios termos e, ainda, ser reconhecido como um membro da dinastia Teodosiana, já que seu filho Hunerico havia se casado com Eudocia, filha de Valentiniano III. Ele também apresenta a tentativa de Genserico em intervir na política imperial, ao nomear Olybrius como imperador no Ocidente em 461 e 465. Olybrius era casado com Placídia, a filha mais nova de Valentiniano III e, portanto, junto de Hunerico faziam parte da nova geração da dinastia Teodosiana. Embora Genserico não tenha obtido sucesso nessa nomeação, o autor apresenta que a tentativa de nomeação de um imperador demonstra o potencial político em ascensão do Reino Vândalo.

No quinto capítulo, o autor se propôs a discutir as sucessões do Reinado Vândalo de Hunerico (477-484) a Gelimero (530-533) e apresenta o processo de concentração de poder político e aristocrático na família de Genserico durante todo o reinado na África. É possível, inclusive, conferir na página 240 uma árvore genealógica que apresenta a sucessão e os descendentes de Genserico, colocado como figura central. Nesse capítulo, Steinacher também apresenta a condução política e religiosa que reafirmava a associação entre vândalos e arianos e, por conta disso, revela que a situação dos clérigos católicos havia sido inconstante: por vezes eram perseguidos e exilados, e eventualmente tolerados.

No capítulo seis, Steinacher aborda o período entre 533 e 551, analisando as guerras entre o Reinado Vândalo e o Império do Oriente sob Justiniano e o período da África Bizantina e sua interação com a população africana e vândala. Estas promoveram grandes revoltas e tentativas de insurgência durante o período bizantino, principalmente contra o aumento expressivo dos impostos e a desapropriação das famílias dos soldados vândalos em benefício dos novos burocratas romanos que ali se estabeleciam. Nesse capítulo, o autor apresenta uma narrativa bastante descritiva sobre as guerras, os conflitos e mesmo sobre as motivações que levaram Justiniano a intervir na África Vândala. Nesta questão, Steinacher parece trazer uma perspectiva ainda não explorada, na qual o imperador Justianino e seu general Belisário não teriam o objetivo de reconquistarem esses territórios, mas antes de promover uma intervenção rápida para depor o rei Gelimero, que havia usurpado o trono de Hilderico, neto de Valentiniano III e, portanto, diretamente associado à dinastia Teodosiana através da união de seus pais Hunerico e Eudocia. 
Desse modo, o autor considera que Justiniano havia considerado a deposição de Hilderico como um ataque à própria ordem dinástica do Império Romano e, assim, a expedição militar enviada pelo imperador deveria apenas reestabelecer o reinado de Hilderico. Roland Steinacher inclusive apresenta que o número pouco expressivo de tropas enviadas à África não seria compatível com o objetivo de reconquista. Entretanto, após os conflitos iniciais e os sucessivos erros estratégicos e militares do rei Gelimero, a ocupação de Cartago por Belisário e seu exército foi inevitável, levando a um novo marco de domínio romano.

No sétimo e último capítulo, Steinacher se dedicou a apresentar um panorama geral e bastante amplo sobre a percepção da historiografia sobre os vândalos, dos séculos VI, a partir de Gregório de Tours, até os anos finais do século XVIII, quando o bispo de Blois, Henri-Baptiste Grégoire, foi responsável por cunhar o termo "vandalismo", usado como figura de linguagem para se referir à destruição promovida pelos jacobinos contra prédios reais e representações monárquicas. Esta perspectiva serve para avaliarmos um panorama geral dos preconceitos e negatividades sobre a História dos Vândalos que foram reproduzidos na historiografia desde o período medieval e que perdura até os dias atuais. Outra discussão que também deve ser considerada aqui é que, para o autor, as descobertas arqueológicas a partir do período moderno motivaram alguns Estados-Nações como Polônia e Suécia a competirem pela herança vândala, e até mesmo pela identidade ancestral vândala, que havia sido associada aos povos germânicos, mas que em outras ocasiões e situações também foram representados como eslavos. Um meio termo, no entanto, foi assumido por Albert Krantz para encerrar com as hostilidades e colaborar na manutenção da Liga Hanseática: ele defendeu que os vândalos representavam uma identidade mais ampla que pode ser associada às ancestralidades dos povos da Liga, determinando assim uma ligação cultural em comum entre essas nações. Essa discussão parece ter sido desenvolvida por Steinacher como introdução às discussões que são desenvolvidas no Apêndice de seu livro.

No apêndice do livro, o autor parece orientar uma conclusão sobre as discussões iniciadas no capítulo sete. Aqui ele esclarece suas percepções sobre os debates sobre uma identidade ancestral vândala, isto é, anteriores à sua migração para o Império Romano. Deste modo, ele considera que o termo vândalo utilizado pela etnografia romana deve estar associado à compreensão de grupos mais amplos, não somente aquele que atravessou as fronteiras do Danúbio no início do quinto século. Isto porque, segundo ele, 
Mare Nostrum, ano 2020, v. 11, n. 1 .

os etnógrafos dos séculos I até o III seguiam um modelo que associava povos a lugares, nesse caso utilizando o termo vândalo para descrever os povos que viviam entre os rios Oder e Vístula. Este, por sua vez, foi utilizado pela historiografia moderna para a reivindicação de territórios a reinos e nações emergentes. Steinacher também parece se preocupar com a etnogênese vândala de forma mais explícita em seu apêndice, ao retomar as discussões desenvolvidas no primeiro capítulo e apresentar as associações entre a cultura Przeworsk com as tradições etnográficas para defender o ponto de partida geográfica e identitária na região da Polônia. Com o aumento expressivo da cultura Wielbark, que Steinacher julga como sendo representativa de comunidades godas, Steinacher acredita que a cultura Przeworsk teria entrado em declínio, posição que consequentemente colabora para a compreensão das disputas e rivalidades existentes entre vândalos e visigodos no século $\mathrm{V}$.

Deste modo, o apêndice parece refletir a preocupação de Steinacher em localizar uma História dos Vândalos como sendo uma comunidade mais ampla, tanto em extensão identitária como em sua História, mas que infelizmente esbarra em incertezas devido às grandes lacunas temporais, que não são desconsideradas por ele. Logo, este item poderia apresentar uma conclusão do livro, mas sem considerações absolutas e irrefutáveis. Pelo contrário, o autor parece querer abrir um caminho para novas e crescentes pesquisas que visem explorar as identidades desse povo que ainda sofre com o preconceito do imaginário popular.

Recebido em 05.03.2020, aprovado em 27.05.2020. 
Geraldo Rosolen Júnior. Resenha de Steinacher, R. (2016).

\section{REFERÊNCIAS BIBLIOGRÁFICAS}

Berndt, G. M. \& Steinacher, Roland. (Eds. ). (2008). Das Reich der Vandalen und seine (Vor)-Geschichten. Verlag der Österreichischen Akademie der Wissenschaften.

Pohl, W. (2005) Die Völkerwanderung. Eroberung und Integration. Kohlhammer.

Pohl, W. (2013). Barbarian migrations (Völkerwanderung). In Ness, I. (Ed.). The Encyclopedia of Global Human Migration. Wiley-Blackwell.

Steinacher, R. (2016). Die Vandalen: Aufstieg und fall eines barbarenreichs. Klett-Cotta.

Steinacher, R. (2017). Wanderung der Barbaren? Zur Entstehung und Bedeutung des Epochenbegriffs ,Völkerwanderung‘ bis ins 19. Jahrhundert. In Wiedemann, F., Hofmann, K. P. \& Gehrke, H.-J. (Eds.). Vom Wandern der Völker. Migration Erzählungen in den Altertumswissenschaften. Edition Topoi. 